Article

\title{
A Study on Project Duration Incentives in a Retail Apparel Franchise
}

\section{Yichen Peng ${ }^{1,2, *}$, Jing Zhou ${ }^{2}$ and Xiaoling $\mathrm{Wu}^{2,3}$}

1 School of Business Administration, Nanjing University of Finance \& Economics, Nanjing 210046, China

2 School of Management and Engineering, Nanjing University, Nanjing 210093, China; E-Mails: jzhou@nju.edu.cn (J.Z.); xiaoling_wu@126.com (X.W.)

3 School of Economics and Management, Nanjing Tech University, Nanjing 210009, China

* Author to whom correspondence should be addressed; E-Mail: jzhou@nju.edu.cn or pyc114@hotmail.com.

Academic Editors: Tsan-Ming Choi and Yongjian Li

Received: 30 October 2014 / Accepted: 12 February 2015 / Published: 16 February 2015

\begin{abstract}
This paper studies the impact on project duration of different forms of over-confidence among general contractors executing such projects, in the context of retail apparel franchises. It goes on to consider the design of relevant incentives and, in particular, a compensation mechanism included in the initial contract that covers the event of contractor dismissal. This mechanism is examined as a means of hedging risk arising from the behavior of the principal. This includes a study of a two-way risk avoidance strategy, which is intended to make up for a shortfall in this regard in the existing literature. Outcomes derived from this research include the conclusion that different levels of confidence can have various impacts on optimal incentive coefficients and the effort level extracted from agents, thereby affecting the ultimate configuration of an optimal contract. Introducing a compensation mechanism covering the event of dismissal can serve to diminish the risk of an agent breaching their contract. This paper applies the concept of bounded rationality to a principal-agent model, ensuring conclusions that are attuned to reality.
\end{abstract}

Keywords: franchise; apparel branding; clothing branding; project duration incentives; over-confidence; two-way risk 


\section{Introduction}

Franchises are considered the dominant business model of the 21 st century. They flourish in emerging markets such as China and are widely adopted because of their low cost, especially in the clothing retail industry. Most international and domestic Chinese brands rely on franchising for rapid expansion. Many disappear overnight, however, in the face of fierce competition; few make steady progress in terms of market share. Nevertheless, the IPO of Heilan Home Co. aroused considerable interest as a result of the company's relatively innovative franchising model. Heilan Home came into existence in 2002, and its main product is men's clothing. After 12 years of endeavor, it has developed into a listed company with a market value of US\$6.5 billion and more than 3200 franchised outlets [1]. Its unique business model accounts for its success, and studying this model is necessary.

There are three ways by which a clothing brand usually charges a franchise fee: fixed price, cost proportionate to revenue, or a fixed price-equity share hybrid. Granted a concession period by the franchisor, the licensee is responsible for the operation of the store, and yields profit from the brand during this period. Take Heilan Home as an example: Heilan Home combines a franchise fee with a franchise option, and requires a one-off lump-sum payment. If the licensee exits at the end of the franchise contract term, the ownership of the franchise store returns to Heilan Home. It is well known that in the branded apparel industry, issues arising from both fashion and season play an important role in terms of determining customer requirements. This creates uncertainties in this sector and makes time an important factor, vital to the success of firms such as Zara that are predicated on high inventory turnover. From construction to operation, the time factor should be considered in every aspect of the fashion industry.

Usually, the licensee provides the fee for building and decoration, while the franchisor seeks a contractor to build and fit the store, creating a typical principal-agent relationship, i.e., franchisor/ licensee-contractor (shown as Figure 1).

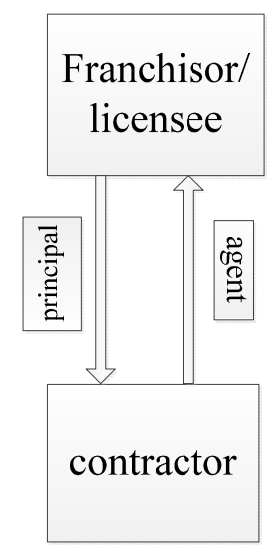

Figure 1. Relationship between the parties.

Under the condition that the franchise period, which is divided into two parts - construction period and operating period - is determined, the construction period determines the store's future profits and is therefore considered a critical element in the construction contract. If the period is restricted to a suitable length, the operation period will be extended and the licensee will seize more business opportunities to gain more profit. Therefore the licensee hopes the construction will finish earlier. However, if the 
construction period is too short, the quality of the final store can be negatively impacted, as well as raising the contractor's costs, resulting in less retained value on expiry of the franchise period [2]. Accordingly, the incentives applied by the principal to the agent, if properly configured, can maximize future profits [3], and have therefore always been a subject of heated debate in construction contracts, especially for the franchise model.

Existing research mainly focuses on traditional principal-agent models. Etgar et al. [4] discuss incentives focusing on project duration from the perspective of the principal; Avraham Shtub [5] examines the effect of single impact factors on project workflows. Tareghian et al. [6] suggests that cost minimization and resource redistribution may be calibrated to ensure appropriate project duration incentives. Lambropoulos [7] argues that well-run projects should focus on profit maximization as opposed to cost minimization, and that therefore the principal should offer incentives for agents to increase construction efficiency and shorten the construction period. Nevertheless, given that stipulations as to construction efficiency may not be observed and agents may seek only to maximize profits, moral hazards certainly remain.

The analyses referred to above, however, are undertaken within a traditional principal-agent framework, which considers only moral hazard pertaining to the agent. There are two major flaws in this premise. Firstly, it fails to account for the risk of the principal's default, leading to delay or cancellation of the project; this can increase the agent's costs and lower its profits. Secondly, the rational person actor hypothesis does not account for the impact of psychological factors on decision-making. Numerous studies have shown the intrinsic deficiencies of the principal-agent model-based on traditional information economics - stemming from game theoretical arguments based on fairness preference frameworks, along with reciprocal altruism. It fails to explain phenomena such as low sensitivity to performance-based rewards. The actions of real decision-makers are never so clear-cut and rational, with social and psychological factors affecting individual judgment, assessment and decision-making capacities, resulting in skewed cognition, excess emotion and curtailed agency [8]. Loss aversion, over-confidence, optimism, psychological state, rigid expectations, conservative dispositions, and level of experience represent typical causes of bias [9-11]. Traditional principal-agent models therefore fail to elucidate the real decision-making processes of principals and agents, distorting incentives and leading to reductions in efficiency.

Psychological studies at the end of the 20th century tended to conclude that the most stable and meaningful characteristic of individuals was overconfidence. Debondt and Thaler [12] noted that overconfidence is one of the most predictable psychological states. This has become one of the most important means of expanding conceptions of bounded rationality. Most policymakers demonstrate a propensity for overconfidence, which arises from faith in their own knowledge, ability and the accuracy of the information they receive [13-15]; as such, they typically over-estimate the value of these factors and the likelihood of their own success. Overconfidence prevails among the psychological distortions on economic behavior and explains deviations from economic principles. Some researchers focus on overconfidence and optimizing incentives from the perspective of designing the principal-agent contract. Keiber [16] takes the overconfidence levels of both principal and agent into account, discovering that optimal contract design conditions occur when overconfidence is at the same level on both sides. Fang and Moscarini [17] studied overconfidence in the context of contractual payments and concluded that it helps to save on incentive costs. Chen and Yang [18] found that the optimal level of 
effort exerted by the agent would always increase the overconfidence level of the agent, and the optimal intensity of monitoring of the principal in equilibrium would always decrease the overconfidence level of the agent. Yan et al. [19] introduced overconfidence bias into the multi-task principal-agent model, and thus amended the basic frame of the multi-task principal-agent model and some conclusion. Zhang and Huang [20] showed that the principal should offer different forms of compensation contracts to agents with different overconfidence degrees. In another study, they tested theoretical optimal solutions by controlling the risk attitude of the CEO, who is an agent of stakeholders, and confidence level through experiments. Their experiments showed that the agent's risk attitude and confidence level did influence their optimal compensation [21].

Existing studies do not take the overconfidence factor into account, however, when modeling project duration incentives; they also neglect the risk of default by the principal and subsequent effects on contractual incentives. Some studies that touch on the principal-agent model include overconfidence, but are limited by overestimation of risk control and direct payoffs. They all ignore an additional form of overconfidence, however: underestimation of project costs, which prevents the principal from forming a reasonable expectation of project duration. This paper attempts to analyze this in the context of a fashion franchise business's construction projects, where franchise duration is fixed; it combines the franchisor or licensee default scenario with contractor overconfidence, and proceeds to discuss optimal incentive configuration when dealing with an overconfident contractor from the principal's perspective. The paper also analyzes the impact of overconfidence on effort levels, the optimal incentive coefficient, fixed returns, and opportunity costs. By introducing a dismissal compensation mechanism in the initial contract to suppress risks entailed by the principal's behavior, the limitations inherent in only considering one side's moral hazard - exhibited in existing studies of project duration incentives - was precluded from the present study. This paper concludes that agent overconfidence impacts the efficacy of contractual incentives pertaining to project duration. In the existing literature, different forms of overconfidence have been shown to have various impacts on the optimal incentive coefficient and the effort level of agents. Relatedly, this paper identifies dismissal compensation mechanisms as effective in ameliorating default risk for the principal. The default rate and compensation amount will also affect the arrangement of project duration incentives in the contract.

The organization of this paper is as follows: an illustrative example of project duration-related incentives is introduced subsequently in Section 2. In Section 3, we establish an incentive model incorporating overconfidence to promote contractually agreed project duration. Then, in Section 4, we solve the model and design optimal contractual incentive mechanisms when construction efficiency is not observable and observable, respectively. Finally, we state our conclusions in Section 5.

\section{An Illustrative Example of Project Duration-Related Incentives}

In practice, generally, the franchisor will contractually entrust the project to a general contractor; the contract will - through various mechanisms - compel the contractor to complete the project as soon as possible. If the contractor completes the project ahead of the schedule stipulated in the contract, the licensee - as principal - would reward the agent-contractor. If the contractor does not complete it on time, the licensee would punish the contractor according to the conditions laid down in the contract. The contractual incentives related to project duration may be expressed thusly: 


$$
w(t)=\omega_{0}+\omega_{1}\left(t_{0}-t\right)
$$

In this formula, to represents the project duration stipulated in the contract; $t$ stands for the actual time taken; when the contractor completes the project within the time stipulated in the contract, a fixed profit of $w_{0}$ is paid, and there is no reward or punishment. The expression $w_{1}$ stands for the reward or punishment received by the contractor per unit of time - the incentive or disincentive-based on whether the project is completed in advance or delayed.

The actual duration of the construction phase of the project, $t$, is not only related to the effort expended by the contractor, but also dependent on the external environment. It can be stated as:

$$
t=t(e, \theta)=\frac{k}{e}+\delta \theta
$$

The expression $e$ within the formula represents the contractor's effort. Here we regard it as construction efficiency; $k$ stands for the overall work of the project; $\theta \sim N\left(0, \sigma^{2}\right)$ is a random variable representing the influence of environmental factors on actual project duration; $\delta$ stands for the impact of random external factors on project duration.

Accurately accounting for the contractor's effort-or construction efficiency - is problematic under the principal-agent framework. Equally challenging is obtaining an accurate prediction of uncertainties arising from the external environment. The contractor can utilize information superiority and delineate a construction efficiency that maximizes its own interests, as well as ascribing delay to the project to the uncertainty of the external environment. Moral risks also exist on the agent-contractor's side; to prevent this, the licensee adopts incentives and disincentives, which are applied according to the actual state of the project on the agreed date of completion. This prompts the contractor to adopt an efficient approach to construction, which meets the licensee's own interests. Nonetheless, from the contractor's perspective, there are also default risks as a stakeholder in the contract. The most effective way to prevent risk of default by the principal is to stipulate dismissal compensation to the agent in the initial contract [22]. In other words, when the principal and the agent agree on the initial contract, it should make provisions for circumstances in which the principal dismisses the general contractor with no reasonable excuse. In such a situation, a payment of $B$ to the agent is triggered by way of compensation and, after the dismissal, the principal hires another contractor to bring the average efficiency level to R'. Under this mechanism, the behavioral risks on both sides can be, to some degree, specified in the design of the contract. The aim of this article is to design a contract that ensures the interests of both sides are maximized.

\section{An Incentive Model Incorporating Overconfidence to Promote Contractually Agreed Project Duration}

\subsection{Model Building}

In a given project, the franchise period is $T$ years. A predicted average profit of $R$ per annum is achieved during the operating portion of the franchise period. According to formula (2), the licensee's actual profit is: 


$$
\pi=\pi(e, \theta)=R[T-t(e, \theta)]
$$

Formula (3) shows that expected project duration will influence the licensee's actual operating time within the franchise period. If the contractor completes the project ahead of schedule, the licensee can attain a longer operating period and, therefore, larger profits. In contrast, if the contractor completes the project behind schedule, the licensee would have a shorter operating period and therefore fewer profits.

The overall project cost, $C$, is calibrated to include two parts: construction costs and maintenance costs during the operating period. To simplify this calculation, we take $C$ to be constant. As explained above, the principal bears a default risk, $p$. If the principal breaches the contract with no reasonable excuse, it is required to pay a compensatory sum of $B(e, p)$ to the contractor. Therefore, the expected utility accrued by the licensee can be formulated as:

$$
E_{\theta}\left\{v\left((1-p)[\pi(e, \theta)-w(t(e, \theta))-C]+p\left(R^{\prime}-B\right)\right)\right\}
$$

Within this formula, $v(\bullet)$ represents the utility function of the licensee.

Using formula (4) as the object function, the licensee's target is to maximize expected utility by selecting a suitable incentive mechanism for the contract $w$. Under the principal-agent model, however, this optimization problem must still address two constraints, namely the "agent-contractor participation constraint" and the "incentive compatibility constraint." Supposing a total construction cost of c(e) was paid by the contractor as a function of construction efficiency, its expected utility may be formulated thusly:

$$
E_{\theta}\{u((1-p)(w(t(e, \theta))-c(e))+p B)\}
$$

Within this formula, $u(\bullet)$ represents the contractor's expected utility function.

The participation constraint — also called reservation utility_-renders the expected utility obtained by the contractor on execution of the contract no less than that obtained upon dissolution of the contract. Reservation utility is determined by the other market opportunities available to the contractor; if set as $\bar{\mu}$, the participation constraint maybe formulated thus:

$$
E_{\theta}\{u((1-p) w(t(e, \theta))-c(e)+p B)\} \geq \bar{\mu}
$$

The incentive compatibility constraint aims to prevent moral risk arising from the contractor. Incentives adopted by the principal should allow the contractor to choose a rate of construction that maximizes its expected efficiency. This is because it is undesirable to observe a rate of construction chosen by the contractor. The licensee can therefore only achieve its most desirable outcomes by maximizing the contractor's expected utility. The incentive compatibility constraint can be formulated thus:

$$
E_{\theta}\{u((1-p) w(t(e, \theta))-c(e)+p B)\} \geq E_{\theta}\left\{u\left((1-p) w\left(t\left(e^{\prime}, \theta\right)\right)-c\left(e^{\prime}\right)+p B\right)\right\}
$$

This demonstrates that-when the contractor chooses other rates of construction $e^{\prime}$ (i.e., not the optimal rate of construction $e$ ) - the expected utility secured is no greater than the expected utility obtained by choosing the optimal rate of construction. In other words, construction efficiency-as chosen by the contractor-maximizes the interests of the licensee and the contractor itself; this incentive mechanism compels the contractor to choose an optimal level of construction efficiency.

This problem can be formulated in a principal-agent model, thus: 


$$
\begin{gathered}
\max _{w(t)} V=E_{\theta}\left\{v\left((1-p)[\pi(e, \theta)-w(t(e, \theta))-C]+p\left(R^{\prime}-B\right)\right)\right\} \\
\text { s.t. } E_{\theta}\{u((1-p)(w(t(e, \theta))-c(e))+p B)\} \geq \bar{\mu} \\
\max _{e} U=E_{\theta}\{u((1-p)(w(t(e, \theta))-c(e))+p B)\}
\end{gathered}
$$

\subsection{A Mathematical Illustration of Over-Confidence}

The various manifestations of overconfidence maybe summarized as follows. People usually overestimate their ability and believe themselves to be capable of achieving more than others given the same level of effort. In other words, decision-makers - expending less effort but holding decisive positions within particular projects - usually exhibit greater overconfidence than other participants in the project. People tend to overestimate the accuracy of their knowledge and the information they can marshal. They believe their retrieval, collection and analysis of information can be undertaken without error, meaning that their information is complete and persuasive. Furthermore, most people believe their abilities are above average and assign a higher level of proficiency to themselves as a result of self-evaluations than when they evaluate the performance of others. They also tend to internally prioritize experiences of success over experiences of failure, thereby overrating their own contributions to the successes of projects in which they have been involved. Contemporary scholarship describes the phenomena outlined above - encapsulated by the term 'overconfidence'-using the following mathematical models:

(1) Gervais and Goldstein [23] define the level of overconfidence as $d=A-a$, with $d>0$ standing for the overconfident actor's perception of their ability level, and $A$ as the overconfident actor's actual ability level.

(2) When analyzing the influence of the external environment on the decision outcome, Keiber (see reference [16]) argues that the distribution of random variable $\varepsilon$, which describes the external environment, is usually set to meet a normal distribution $\mathrm{N}\left(0, \delta^{2}\right)$. Since overconfident actors tend to overestimate their own competence and mastery of the facts, they assume their ability to control the risk is higher. They think they can control the risk within a relatively small range, expressed as $k \delta^{2}$. With $k$ describing the level of overconfidence, when $0<k<1$ denotes that the decision-maker is overconfident, the smaller the value of $k$, the higher the level of overconfidence.

By referring to the theories above, this article draws on the definition of overconfidence provided by reference [24], positing that the overconfident agent-contractor overestimates its competence. Given the same level of profit, the overconfident agent considers its effort cost to be lower than the actual cost; in other words, the coefficient of the effort cost is lower than that of a rational agent, and a relatively large profit level is therefore attained.

\subsection{Basic Assumptions}

Assumption 1: This article assumes the future net proceeds per unit of time $R>0$, meaning the attainable future profits of the licensee can cover costs, including construction and maintenance costs.

Assumption 2: The overconfidence of the contractor-agent is demonstrated by its skewed anticipation of the future. A lower level of cost than is actually required is estimated as sufficient given a 
desire to maximize profits. Furthermore, construction cost and cost margins are presumed to increase in line with the promotion of construction efficiency, i.e., $d c(e) / d e>0, d^{2} c(e) / d e^{2}>0$, so

$$
c(e)=\gamma \beta e^{2} / 2
$$

Assuming therefore that the coefficient of construction cost is $\beta>0$, meaning the greater the value of $\beta$, the lower the technical merit of the contractor's work; in contrast, the lower the value of $\beta$, the higher the technical merit of the contractor's work. $\gamma(0<\gamma<1)$ stands for the coefficient of the contractor's over-confidence. The greater the value of $\gamma$, the lower the level of the contractor's overconfidence, and the closer expected construction costs will be to actual costs. In contrast, the lower the value of $\gamma$, the greater the level of contractor overconfidence, and the further its expected construction costs will be from actual costs.

Assumption 3: The risk neutrality of the principal-licensee and the risk aversion of the agent-contractor, and the utility function, are constant and absolute features of risk aversion. This assumption means that the licensee's expected utility is equal to its expected profits. Conversely, the utility function of the contractor-wishing to avoid the influence of uncertain external factors on project duration - features risk aversion in the following manner:

$$
u(X)=-\exp (-\rho X)
$$

Here, $\rho>0$ represents the absolute degree of risk aversion exhibited by the contractor, whereas $\rho=0$ represents the risk neutrality of the contractor.

Assumption 4: The probability of the principal's default before project commencement is expressed as $p$. Dismissal compensation stipulated in the initial contract is $B$, which includes the contractor's effort cost in winning the contract and compensation for the contractor's other losses. $B$ is a function of the probability of default $p$, and meets $\partial B / \partial p>0$. This means that the higher the tendency of the principal towards default, the greater the compensatory default penalty will be.

\section{Solving the Model and Designing Optimal Contractual Incentive Mechanisms}

This article analyzes the impact of the agent's overconfidence on contractual design in light of whether the contractor's construction efficiency is observable or not. It offers the optimal form of incentives as those illustrated in the principal-agent model expressed above.

\subsection{Optimal Contractual Incentives for Observable Construction Efficiency}

When it is possible to observe the construction efficiency of the contractor on a project, the licensee can use a contract to compel the contractor to choose a level of construction efficiency that maximizes its own profits based on the participation constraint. In these circumstances, there is no need to consider the incentive compatibility constraint. Based on Assumption 3, the contractor is a risk-aversive decision-maker; its utility function meets Formula (9) and, substituting Formula (5) into Formula (9), its certainty equivalent income can be formulated thus:

$$
\bar{U}=p B+(1-p)\left[\omega_{0}+\omega_{1}\left(t_{0}-k / e\right)-\gamma \beta e^{2} / 2\right]-\rho(1-p)^{2} \omega_{1}^{2} \delta^{2} \sigma^{2} / 2
$$


This means the expected utility obtained by the contractor can be expressed as the income obtained from certainty equivalent income $\bar{U}$. In addition, Formula (9) demonstrates that the contractor's utility function is an increasing function; therefore when contractor's construction efficiency is observable, this problem can be formulated using the following model:

$$
\begin{gathered}
\max V=p\left(R^{\prime}-B\right)+(1-p)\left[R(T-k / e)-\omega_{0}-\omega_{1}\left(t_{0}-k / e\right)-C\right] \\
\text { s.t. } \bar{U}=p B+(1-p)\left[\omega_{0}+\omega_{1}\left(t_{0}-k / e\right)-\gamma \beta e^{2} / 2\right]-\rho(1-p)^{2} \omega_{1}^{2} \delta^{2} \sigma^{2} / 8 \bar{\omega}
\end{gathered}
$$

In this instance, $\bar{\omega}$ stands for the opportunity profit of the contractor, $u(\bar{\omega})=\bar{\mu}$. Formula (12) indicates that the contractor's participation in this is conditional on fulfilling the requirement that its certainty income is no less than its opportunity income.

To solve this model, its Kuhn-Tucker Conditions may be considered as follows:

$$
\left\{\begin{array}{l}
\frac{\partial V}{\partial e^{*}}+\lambda \frac{\partial U}{\partial e^{*}}=0 \\
\frac{\partial V}{\partial \omega_{0}^{*}}+\lambda \frac{\partial U}{\partial \omega_{0}^{*}}=0 \\
\frac{\partial V}{\partial \omega_{1}^{*}}+\lambda \frac{\partial U}{\partial \omega_{1}^{*}}=0 \\
\lambda(\bar{U}-\bar{\omega})=0
\end{array}\right.
$$

$\lambda \geq 0$ is the Kuhn-Tucker multiplier of the model, and solving this set of equations offers a result of $\lambda=1$. The optimal result of the problems above is:

$$
\begin{gathered}
e^{*}=\left[\frac{R k}{\gamma \beta}\right]^{1 / 3} \\
\omega_{1}^{*}=0 \\
\omega_{0}^{*}=\frac{\bar{\omega}-p B}{1-p}+\frac{\beta \gamma e^{2}}{2}
\end{gathered}
$$

This means the licensee's optimal expected profit is:

$$
V=p\left(R^{\prime}-B\right)+(1-p)\left[R\left(T-\frac{k}{e^{*}}\right)-\omega_{0}^{*}-C\right]
$$

Several conclusions can be drawn in light of the contract's optimal results as follows:

(1) When there is symmetry of information, the licensee's optimal expected profit is irrelevant to the incentive coefficient $\omega_{1}$. Concurrently, the licensee does not need to take action to incentivize the contractor because the contractor's construction efficiency can be observed. They can then ask the contractor to meet a particular level of preferred construction efficiency that maximizes the licensee's expected profits. Therefore, only a certain amount of fixed income, $\omega_{0}^{*}$, must be paid without the addition of incentives.

(2) $\frac{\partial \omega_{0}^{*}}{\partial \gamma}=\frac{\left[R^{2} k^{2} \beta\right]^{1 / 3} \gamma^{-2 / 3}}{6}>0, \frac{\partial e^{*}}{\partial \gamma}=-\frac{1}{3}\left[\frac{R k}{\beta}\right]^{1 / 3} \gamma^{-4 / 3}<0$. The fixed amount paid by the licensee to the contractor correlates negatively with the contractor's confidence level. In other words, the higher the 
contractor's confidence levels, the lower the fixed amount it can obtain. This is because a higher confidence level entails a lower estimate of effort cost by the contractor. Accordingly, the licensee offers a lower payment amount. However, the optimal construction efficiency chosen by the contractor positively correlates with the level of overconfidence; the higher the confidence levels - the lower the value of $\gamma$-and the higher the optimal effort level chosen by the contractor. Even if the licensee is unwilling to offer a larger fixed payment, a confident contractor would still be willing to make substantial effort because it underestimates its own effort costs.

However, when the contractor's construction efficiency is not observable, the contractor will choose an effort level that maximizes its own interests. Therefore, the licensee should deploy incentives that will ensure the contractor conforms to its objectives and interests.

\subsection{Optimal Contractual Incentives When Construction Efficiency Is Not Observable}

When construction efficiency is not observable, the licensee can use the incentive compatibility constraint to optimize contractor efficiency and prevent moral hazard. According to Formula (10), incentive compatibility constraint may be expressed as:

$$
\max _{e} \bar{U}=p B+(1-p)\left[\omega_{0}+\omega_{1}\left(t_{0}-k / e\right)-\gamma \beta e^{2} / 2\right]-\rho(1-p)^{2} \omega_{1}^{2} \delta^{2} \sigma^{2} / 2
$$

The first derivative of Formula (17) represents the optimal strategy:

$$
\frac{\partial \bar{U}}{\partial e^{*}}=0 \Rightarrow e^{*}=\left[\frac{\omega_{1} k}{\beta \gamma}\right]^{1 / 3}
$$

Therefore, the optimal contract design for the licensee can be explained thus:

$$
\begin{gathered}
\max V=p\left(R^{\prime}-B\right)+(1-p)\left[R\left(T-k / e^{*}\left(\omega_{1}\right)\right)-\omega_{0}-\omega_{1}\left(t_{0}-k / e^{*}\left(\omega_{1}\right)\right)-C\right] \\
\text { s.t. } \bar{U}=p B+(1-p)\left[\omega_{0}+\omega_{1}\left(t_{0}-k / e^{*}\left(\omega_{1}\right)\right)-\gamma \beta e^{*}\left(\omega_{1}\right)^{2} / 2\right]-\rho(1-p)^{2} \omega_{1}^{2} \delta^{2} \sigma^{2} / 2 \geq \bar{\omega}
\end{gathered}
$$

According to Kuhn-Tucker Theorem, this model equates to:

$$
\begin{aligned}
& \max _{\omega_{1}} V=p\left(R^{\prime}-B\right)+(1-p)\left\{R\left(T-k\left[\omega_{1} k / \beta \gamma\right]^{-1 / 3}\right)-C\right\}-\bar{\omega}+p B \\
& -\rho(1-p)^{2} \omega_{1}^{2} \delta^{2} \sigma^{2} / 2-(1-p) \beta \gamma\left[\omega_{1} k / \beta \gamma\right]^{2 / 3} / 2
\end{aligned}
$$

By solving the model, we obtain the following propositions:

Proposition 1: When the contractor is overconfident, the optimal contract, $\omega_{1}{ }^{*}$ fits in with:

$$
g\left(\omega_{1}^{*}\right)=3 \rho(1-p) \delta^{2} \sigma^{2} \omega_{1}^{7 / 3}-k^{2 / 3}[\beta \gamma]^{1 / 3}\left(R-\omega_{1}\right)=0
$$

In an optimally incentivized contractual arrangement, the licensee's fixed payment, $\omega_{0}^{*}$ is:

$$
\omega_{0}^{*}=\frac{\bar{\omega}-p B}{1-p}+\frac{3\left(\beta k^{2}\right)^{\frac{1}{3}} \gamma^{\frac{1}{3}} \omega_{1}^{* \frac{2}{3}}+\rho(1-p)\left(\omega_{1}^{*} \delta \sigma\right)^{2}}{2}-\omega_{1}^{*} t_{0}
$$

The optimal solution, $\omega_{1}^{*}$ meets the condition, $\omega_{1}^{*} \leq R$ and has the following properties:

(1) $\partial \omega_{1}^{*} / \partial R>0$; (2) $\partial \omega_{1}^{*} / \partial\left(\rho \delta^{2} \sigma^{2}\right)<0$. 
Proof: Since $\frac{\partial g}{\partial \omega_{1}}>0, g\left(\omega_{1}\right)$ is monotonically increasing between $(0,+\infty)$ and $g(0)<0$, $g(+\infty)>0, \omega_{1}^{*}$ is the only solution, the first derivative of the objective function, $\omega_{1}^{*}$ is:

$$
\frac{\partial V}{\partial \omega_{1}}=-\frac{1}{3} \omega_{1}^{-\frac{4}{3}}\left\{3 \rho(1-p)^{2} \delta^{2} \sigma^{2} \omega_{1}^{7 / 3}-k^{2 / 3}(1-p)[\beta \gamma]^{1 / 3}\left(R-\omega_{1}\right)\right\}=-\frac{1}{3} \omega_{1}^{-\frac{4}{3}}(1-p) g\left(\omega_{1}\right)=0
$$

Combining $g(\omega)$ 's monotonically, function $V$ attains the greatest value when $g\left(\omega_{1}\right)=0$, i.e. $\omega_{1}^{*}$ Adding $\omega_{1}{ }^{*}$ into Formula (20), we obtain the solution for $\omega_{0}{ }^{*}$ :

$$
\omega_{0}^{*}=\frac{\bar{\omega}-p B}{1-p}+\frac{3\left(\beta k^{2}\right)^{\frac{1}{3}} \gamma^{\frac{1}{3}} \omega_{1}^{*^{\frac{2}{3}}}+\rho(1-p)\left(\omega_{1}^{*} \delta \sigma\right)^{2}}{2}-\omega_{1}^{*} t_{0}
$$

Since $g(\omega)=0$

$$
R-\omega_{1}^{*}=\frac{3 \rho(1-p) \delta^{2} \sigma^{2} \omega_{1}^{7 / 3}}{k^{2 / 3}[\beta \gamma]^{1 / 3}} \geq 0
$$

Thus, $\omega_{1}^{*} \leq R$, equity holds up if and only if $\rho \delta \sigma=0$. When $\omega_{1}^{*} \neq R$,

$$
\begin{gathered}
\frac{\partial \omega_{1}^{*}}{\partial R}=\frac{\beta^{1 / 3} k^{2 / 3} \gamma^{1 / 3}}{7 \rho(1-p) \delta^{2} \sigma^{2} \omega_{1}^{4 / 3}+k^{2 / 3}[\beta \gamma]^{1 / 3}}>0 \\
\frac{\partial \omega_{1}^{*}}{\partial\left(\rho \delta^{2} \sigma^{2}\right)}=\frac{-3(1-p) \omega_{1}^{7 / 3}}{7(1-p) \omega_{1}^{4 / 3} \rho \delta^{2} \sigma^{2}+k^{2 / 3}[\beta \gamma]^{1 / 3}}<0
\end{gathered}
$$

Proposition 1 is proved.

According to the model's optimal solution and its properties, incentives placed on the contractor by the licensee should not exceed the project's net profits per unit of time. Moreover, the greater the project's future net profits per unit of time, the greater the level of incentives on the contractor. This is because the licensee will adopt stronger incentives in order to stimulate the contractor to complete the construction earlier.

After the contractual incentives have set up dismissal compensation for the project, the first order condition of the principal's expected utility on the default probability $p$ leads to the following:

$$
p=\frac{R^{\prime}-B-\left[R\left(R(T-k / e)-\omega_{0}-\omega_{1}\left(t_{0}-k / e\right)-C\right)\right]}{\partial B / \partial p}
$$

Corollary 1: The introduction of the dismissal compensation mechanism reduces the tendency of the principal to dismiss the contractor; this can effectively restrict the risk of principal default.

Inferring from Formula (24), the dismissal compensation mechanism adds to the cost of principal's default, and therefore prompts the principal to consider such a decision to dismiss the agent more cautiously. As the amount of compensation increases, the probability of the principal dismissing the contractor declines. Conversely, if dismissal occurs and the franchisor or the licensee needs to recruit another contractor, the probability of dismissal would also be affected by the profits that the other contractor would obtain. If the next contractor could produce sufficient profit levels, the licensee would tend to dismiss the current contractor.

According to Formulas (22) and (23), we obtain the following:

$$
\frac{\partial \omega_{1}}{\partial p}=\frac{3 \rho \delta^{2} \sigma^{2} \omega_{1}^{7 / 3}}{7 \rho(1-p) \delta^{2} \sigma^{2} \omega_{1}^{4 / 3}+k^{2 / 3} \beta^{1 / 3} \gamma^{1 / 3}}>0
$$




$$
\frac{\partial \omega_{0}}{\partial B}=-\frac{p}{1-p}<0
$$

Corollary 2: The greater the probability of franchisor or licensee default, the greater the level of incentives expressed in an optimized contract. The higher the level of default compensation, the lower the level of fixed payment that will be offered by the licensee.

From the contractor's perspective, as the probability of the principal's default increases, risk rises; corresponding costs will also increase. The contractor should therefore receive higher incentives in order to cover the risk cost. For the licensee, however, a high probability of default discredits the contractor's capability or suggests more benefit could be obtained from other contractors. If dismissal does not occur, the licensee would tend to apply more incentives in order to complete the construction earlier. In an optimal contract therefore, the higher the probability of principal default, the greater the incentive coefficient. When both sides reach agreement on high levels of dismissal compensation, the penalty cost on the licensee goes up. As a result, the licensee will reduce the fixed payment in order to offset increased hidden costs, meaning that the fixed payment will decrease as the penalty compensation goes up.

According to the optimum condition of the first derivative of overconfidence level $\gamma$ :

$$
\frac{\partial \omega_{1}}{\partial \gamma}=\frac{k^{2 / 3} \beta^{1 / 3}\left(R-\omega_{1}\right)}{21 \rho(1-p) \delta^{2} \sigma^{2} \omega_{1}^{4 / 3} \gamma^{2 / 3}+3 k^{2 / 3} \beta^{1 / 3} \gamma}>0
$$

Corollary 3: When the contractor's construction efficiency cannot be measured or observed, the contractor's overconfidence level increases, and the incentive levels in the contract go down.

Formula (27) explains that the level of the contractor's overconfidence influences the optimum incentive coefficient. Higher levels of contractor overconfidence-meaning the contractor has more confidence in its ability to complete the project at lower levels of cost-entail the licensee providing reduced incentives. Conversely, low overconfidence levels indicate that the contractor has less confidence and therefore estimates higher costs. In this situation, the contractual incentive coefficient is greater.

The first derivative of optimum construction efficiency, $e^{*}$ on the confidence level $\gamma$ is:

$$
\frac{\partial e^{*}}{\partial \gamma}=\frac{1}{3}\left[\frac{k}{\beta \gamma \omega_{1}^{* 2}}\right]^{\frac{1}{3}}\left[\frac{\partial \omega_{1}^{*}}{\partial \gamma}-\frac{\omega_{1}^{*}}{\gamma}\right]
$$

Meaning that when $\frac{\partial \omega_{1}^{*}}{\partial \gamma}>\frac{\omega_{1}^{*}}{\gamma}, \frac{\partial e^{*}}{\partial \gamma}>0$; when $\frac{\partial \omega_{1}^{*}}{\partial \gamma}<\frac{\omega_{1}^{*}}{\gamma}, \frac{\partial e^{*}}{\partial \gamma}<0$.

Corollary 4: When the degree of sensitivity to the optimal incentive coefficient on overconfidence levels exceeds a certain threshold, the contractor's confidence will go down and construction efficiency will increase. When the degree of sensitivity is below this threshold, however, construction efficiency increases as the contractor's confidence level appreciates.

Corollary 4 indicates that - unlike the scenario when construction efficiency is measurable - the correlation between the contractor's efficiency and its confidence level depends on the degree of sensitivity of the principal's incentive mechanism to the contractor's confidence level. When the principal's sensitivity to contractor's confidence coefficient exceeds a certain threshold (the ratio of incentive coefficient to overconfidence level), the contractor's construction efficiency improves as its 
confidence level declines ( $\gamma$ rises). Otherwise, the contractor's level of effort increases as its overconfidence rises; if the appreciation of the principal's incentive coefficient is below a certain threshold - given that principal's incentives decrease as the agent's confidence levels increase - the agent believes that the cost of its efforts are comparatively low and will therefore deploy a higher level of effort. If this appreciation rises above that threshold, however, given that the agent considers the cost of its efforts higher when it is less confident, it still deploys a higher level of effort because now the incentive levels adopted by the principal have increased; the incentive coefficient is more sensitive to the agent's overconfidence level, and therefore the influence of the principal's incentives is greater than the agent's confidence deficit and functions to compensate for the effort expended.

It is worth noting that - unlike the conclusions drawn in the existing literature - this paper argues that there is a negative correlation between the agent's level of overconfidence and its influence on the optimal incentives. Nevertheless, the correlation between effort level and overconfidence is not negative, instead depending on the ratio between the optimum incentive coefficient and the overconfidence coefficient. The agent's level of effort is determined by the combination of effort costs and optimal incentives. This outcome may be largely accounted for by the contrasting measures of overconfidence used in this paper. In the existing work on this subject, most scholars describe overconfidence in principal-agent scenarios mainly in terms of the contractor's confidence in its effective control over future returns, and its confidence that its future earnings will increase. In this paper, however, overconfidence is described in terms of an estimation bias regarding costs. Therefore, the higher the confidence level, the lower the optimal incentive levels. In addition, the existing literature only discusses the effect of overconfidence on contractual design under the principal-agent model, in which the revenue function is assumed to be linear. In contrast, this paper mainly focuses on the incentives applied during construction, where utility functions of the licensee and the contractor are both nonlinear; this results in a distinctive conclusion. Comparing the conclusions of this paper with the existing literature, it maybe claimed that variations between descriptions of overconfidence and utility functions have different influences on optimum principal-agent incentives. There are limitations in the conclusions of the existing literature, and this paper's hypothesis provides a more accurate fit with the operations of real projects.

\section{Conclusions}

Against the backdrop of a construction project by a branded apparel franchise, this paper explores bilateral moral hazard scenarios, optimal incentives adopted by licensee when general contractors are overconfident, behavioral risk arising from a dismissal compensation scheme that restricts the principal, and the influence of overconfidence and dismissal compensation schemes on the contractor's level of effort, optimum incentive coefficient and fixed payment. The main conclusions are listed below.

Firstly, this study demonstrates that bilateral moral hazard must be considered when applying the principal-agent model in the fashion industry; otherwise, optimal contractual incentives cannot be designed. A compensation mechanism can also effectively restrict the risk of principal default. The principal's default costs increase when a dismissal compensation mechanism is introduced. Simultaneously, the probability of dismissal is impacted by benefits brought by other contractors. When 
the benefits are great enough, the principal will tend to dismiss the current contractor. Moreover, the higher the compensation, the lower the fixed payment provided by the licensee.

Secondly, overconfidence has an impact on the decisions of both the principal and the agent in terms of project duration incentives for fashion franchises. When construction efficiency is observable, the higher the contractor's confidence, the lower the attainable fixed payment will be. The optimal construction efficiency adopted by the contractor is positively related to its overconfidence level. A higher confidence level leads to a higher effort devoted by the contractor.

However, when construction efficiency is not observable, the extent of incentives set out in the contract declines as contractor overconfidence increases, which implies that the higher the probability of principal default, the higher the level of incentives will be. If the level of sensitivity of the contractor's overconfidence coefficient to the optimum incentive coefficient exceeds a certain threshold, the lower the level of contractor confidence, the higher the level of contractor's construction efficiency. In contrast, if the level of the corresponding sensitivity is below this threshold, higher contractor confidence results in a higher construction efficiency.

Thirdly, from another perspective, our study, compared to former studies, shows that different forms of overconfidence illustration and contracts may yield different optimal solutions in principal-agent problems. In other words, a conclusion for a linear contract may not be suitable for a nonlinear contract. Thus our study may expand the research on principal-agent problems under the overconfidence assumption.

Moreover, application of this theory requires the assumption of bounded rationality, and a full consideration of the impact of psychological factors on economic behavior. In order to render conclusions more realistic, different expressions of overconfidence in various situations should also be considered, and nonlinear utility functions should be used to determine solutions in future research.

\section{Acknowledgments}

The authors would like to thank the anonymous referees and the editor for their comments. The research was supported by the National Nature Science Foundation of China (70831002).

\section{Author Contributions}

The first author Yichen Peng designed the research by offering the main idea of the paper, and wrote this paper. The second author Jing Zhou offered some important ideas and participated in discussion. The third author Xiaoling $\mathrm{Wu}$ provided the basic project duration incentive model of the paper. All authors read and approved the final manuscript.

\section{Conflicts of Interest}

The authors declare no conflict of interest.

\section{References}

1. Heilan Home becomes the largest clothing enterprises in a shares through back door listing. Available online: http://finance.qq.com/a/20140411/004260.htm (accessed on 11 April 2014). (In Chinese) 
2. Ashley, D.B.; Workman, B.W. Incentives in Construction Contracts; Construction Industry Institute, University of Texas at Austin: Austin, TX, USA, 1986.

3. Bower, D.; Ashby, G.; Gerald, K.; Smyk, W. Incentive mechanisms for project success. J. Manag. Eng. 2002, 18, 37-43.

4. Etgar, R.; Shtub, A.; Leblanc, L.J. Scheduling projects to maximize net present value-the case of time-dependent, contingent cash flows. Eur. J. Oper. Res. 1997, 96, 90-96.

5. Shtub, A.; Leblanc, L.J.; Cai, Z. Scheduling programs with repetitive projects: A comparison of a simulated annealing, a genetic and a pair-wise swap algorithm. Eur. J. Oper. Res. 1996, 88, $124-138$.

6. Tareghian, H.R.; Taheri, H. An application of randomized minimum cut to the project time/cost tradeoff problem. Appl. Math. Comput. 2006, 173, 1200-1207.

7. Lambropoulos, S. The use of time and cost utility for construction contract award under European Union Legislation. Build. Environ. 2007, 42, 452-463.

8. Kahneman, D.; Tversky, A. Prospect theory: An analysis of decision under risk. Econometrica 1979, 47, 263-291.

9. Kahneman, D.; Tversky, A. Judgement under uncertainty heuristic and biases. Science 1974, 185, 1124-1131.

10. Lord, C.; Ross, L.; Lepper, M. Biased assimilation and attitude polarization: The effects of prior theories on subsequently considered evidence. J. Pers. Soc. Psychol. 1979, 37, 2098-2109.

11. Thaler, R. Mental accounting matters. In Choice, Values and Frames; Kahneman, D., Tversky, A., Eds.; Russell Sage Foundation: Cambridge, UK, 1999.

12. De Bondt, W.F.; Thaler, R.H. Financial Decision-Making in Markets and Firms: A Behavioral Perspective; National Bureau of Economic Research: Cambridge, MA, USA, 1994.

13. Langer, E.J. The illusion of control. J. Pers. Soc. Psychol. 1975, 32, 311-328.

14. Weinstein, N.D. Unrealistic optimism about future life events. J. Pers. Soc. Psychol. 1980, 39, 806-820.

15. Taylor, S.E.; Brown, J.D. Illusion and well-being: A social psychological perspective on mental health. Psychol. Bull. 1988, 103, 193-210.

16. Keiber, K.L. Managerial Compensation Contracts and Overconfidence; WHU Otto Beisheim Graduate School of Management: Düsseldorf, Germany, 2002.

17. Fang, H.; Moscarini, G. Overconfidence Morale and Wage-Setting Policies; Yale University: New Haven, CT, USA, 2002.

18. Chen, Q.; Yang, X. Research on Principal-Agent Model Based on Overconfident Agent. J. Ind. Eng. Eng. Manag. 2007, 21, 110-116.

19. Yan, Z.; Zhong, M.; Huang, J. Extended Research of Multi-task Principal—Agent Models Based on Overconfidence. Syst. Eng. 2006, 24, 19-22.

20. Zhang, Z.; Huang, D. Compensation Contract Design for Overconfident Agent with Different Risk Preference. J. Ind. Eng. Eng. Manag. 2009, 23, 104-110.

21. Zhang, Z.; Huang, D.; Xie, J. An Experimental Analysis on the Compensation Contract under Consideration of Overconfidence. J. Shanghai Jiaotong Univ. 2008, 42, 1551-1556.

22. Liu, X.M.; Wen, X.G.; Wu, S.J. Study on double moral hazard prevention based on overconfidence. J. Shanghai Jiaotong Univ. 2010, 44, 373-377. 
23. Gervais, S.; Goldstein, I. Overconfidence and Team Coordination; Duke University: Durham, NC, USA, 2004.

24. Ghosh, M.; John, G. Experimental evidence for agency models of salesforce compensation. Mark. Sci. 2000, 19, 348-365.

(C) 2015 by the authors; licensee MDPI, Basel, Switzerland. This article is an open access article distributed under the terms and conditions of the Creative Commons Attribution license (http://creativecommons.org/licenses/by/4.0/). 